\title{
Auxological and Radiological Manifestations of Patients with Hypochondroplasia Negative for N540K Mutation in Fibroblast Growth Factor Receptor 3 Gene
}

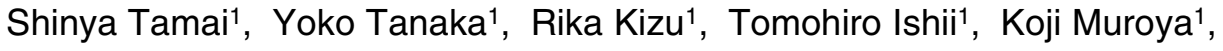 \\ Seiji Sato ${ }^{1}$, Gen Nishimura² and Nobutake Matsuo' ${ }^{1}$ \\ ${ }^{1}$ Department of Pediatrics, Keio University School of Medicine, Tokyo, ${ }^{2}$ Department of Radiology, Nasu Central \\ Hospital,Tochigi, Japan
}

\begin{abstract}
To clarify the auxological and radiological features of hypochondroplasia patients negative for the N540K mutation in FGFR3 gene, eight patients who were radiologically diagnosed as having hypochondroplasia were enrolled in this study (6 males and 2 females); their median age was 10.9 years (range: 5.75-21.75). They were studied for the relationship between auxological and radiological features, and genetic findings. Six patients negative for the N540K mutation had a less severe phenotype, presenting as short stature with less obvious disproportion, with or without relative macrocephaly, and with or without lumbar interpedicular narrowing. These results suggest that hypochondroplasia patients negative for the N540K mutation are heterogeneous in etiology and overlap with constitutional short stature.
\end{abstract}

Key words: hypochondroplasia, fibroblast growth factor receptor 3 (FGFR3), short stature, disproportion, radiological diagnosis

\section{Introduction}

Hypochondroplasia is a skeletal dysplasia of short stature that is inherited as an autosomal dominant trait with variable penetrance. The phenotype of hypochondroplasia varies widely. Patients at the mild end of the spectrum present proportionate short stature with stocky and muscular physique, whereas those at the severe end present disproportionate short stature and

Received: October 6, 2000

Accepted: November 22, 2000

Correspondence: Dr. Shinya Tamai, Department of Pediatrics, Keio University School of Medicine, 35 Shinanomachi, Shinjuku-ku, Tokyo 160-8582, Japan relative macrocephaly of such severity that it can be confused with achondroplasia $(1,2)$.

A heterozygous mutation, resulting in an asparagine-to-lysine substitution at residue 540 (N540K) of the fibroblast growth factor receptor 3 (FGFR3) gene, has been detected in about 60\% of patients diagnosed as having hypochondroplasia $(3,4)$. No demonstrable mutation in the FGFR3 gene, however, has been identified in the remaining $40 \%$ of patients, except for isoleucine-tovaline substitution at residue 538 (I538V) in a Swedish family. The aim of this study was to clarify the auxological and radiological features in hypochondroplasia patients that do not carry the N540K mutation. 


\section{Subjects and Method}

Eight patients (6 males and 2 females) with short stature were enrolled in this study based on the inclusion criteria as described by Prinster et al. (5). They were all sporadic cases and each had at least three of the seven most common radiological findings: 1) narrow or unchanged lumbar interpedicular distance, 2) anteroposterior shortening of lumbar pedicles, 3) dorsal concavity of lumbar vertebral bodies, 4) squared and shortened ilia, 5) short and broad femoral neck, 6) fibula longer than tibia, and 7) mild to moderate brachydactyly (1). The age and gender of each patient are shown in Table 1 . Twenty genetically normal subjects and four patients with achondroplasia, proven to have a glycine-toarginine substitution at residue 380 (G380R) in the transmembrane domain of the FGFR3 gene, were assessed as control groups.

Anthropometric measurement included height, sitting height, ratio of sitting height to leg length (SH/LL ratio), and head circumference. Leg length was calculated by subtracting sitting height from height. The standard deviation (SD) score of each parameter was obtained from standard anthropometry for the Japanese population (6).

Skeletal radiographs were reviewed by S.T. and G.N. who examined all the cases. To quantify the skeletal changes, the ratio of interpedicular distances at the first and fourth lumbar vertebrae
$\left(\mathrm{L}_{1} / \mathrm{L}_{4}\right.$ ratio) was determined to evaluate spinal canal stenosis. The ratio of the interteardrop distance to the pelvic width (I/P ratio) was also calculated to show squaring and shortening of the pelvic ilia (7). The representative radiographs are shown in Fig. 1.

Genomic DNA was extracted from peripheral lymphocytes by the standard phenol-chloroform extraction method. The DNA fragment, covering exons 12 to 14 encoding the entire proximal tyrosine kinase $\left(\mathrm{TK}_{1}\right)$ domain of FGFR3, was amplified with a polymerase chain reaction (PCR), using published oligonucleotide sequences (4). Direct DNA sequencing of both strands of PCR products was performed and analyzed with an ABI PRISM 310 DNA Sequencer (Perkin Elmer, USA). In the N540K-negative group, the presence of the mutation for achondroplasia, G380R of the FGFR3 gene, was excluded by PCR amplification and restriction enzyme digestion analysis as previously described (8).

\section{Results}

The N540K mutation in the heterozygous state was detected in two out of the eight patients with hypochondroplasia. In the remaining six patients negative for N540K mutation, neither sequence variation in the $\mathrm{TK}_{1}$ domain nor the G380R mutation in the transmembrane domain were identified.

Table 1. Summary of patients with hypochondroplasia examined in this study

\begin{tabular}{|c|c|c|c|c|c|c|c|c|c|c|}
\hline \multicolumn{3}{|c|}{ Patients } & \multicolumn{4}{|c|}{ Auxological data (SD scores) } & \multicolumn{4}{|c|}{ Radiological parameters Mutations in FGFR3 } \\
\hline Case & Sex & Age & Standing height & Sitting height & $\mathrm{SH} / \mathrm{LL}$ ratio & Head circumference & $\mathrm{L}_{1} / \mathrm{L}_{4}$ ratio & $\mathrm{I} /$ P ratio & N540K & G380R \\
\hline 1 & M & $9: 10$ & -2.94 & -2.87 & +0.31 & -2.34 & 0.952 & 0.363 & - & - \\
\hline 2 & M & 21:09 & -3.49 & -1.75 & +3.06 & -3.53 & 1.000 & 0.383 & - & - \\
\hline 3 & M & $12: 00$ & -3.12 & -2.10 & +3.00 & +0.53 & 0.950 & 0.402 & - & - \\
\hline 4 & M & 9:06 & -3.01 & -3.08 & -0.35 & +0.31 & 1.000 & 0.379 & - & - \\
\hline 5 & M & $14: 06$ & -5.67 & -3.17 & +5.80 & -1.49 & 0.889 & 0.357 & - & - \\
\hline 6 & $\mathrm{~F}$ & $12: 08$ & -2.12 & -1.35 & +1.30 & +0.83 & 0.957 & 0.375 & - & - \\
\hline 7 & $\mathrm{M}$ & 5:09 & -3.56 & -2.46 & +7.80 & +1.93 & 1.056 & 0.394 & + & n.d. \\
\hline 8 & $\mathrm{~F}$ & $8: 07$ & -2.94 & -1.66 & +7.04 & +1.82 & 1.105 & 0.402 & + & n.d. \\
\hline
\end{tabular}




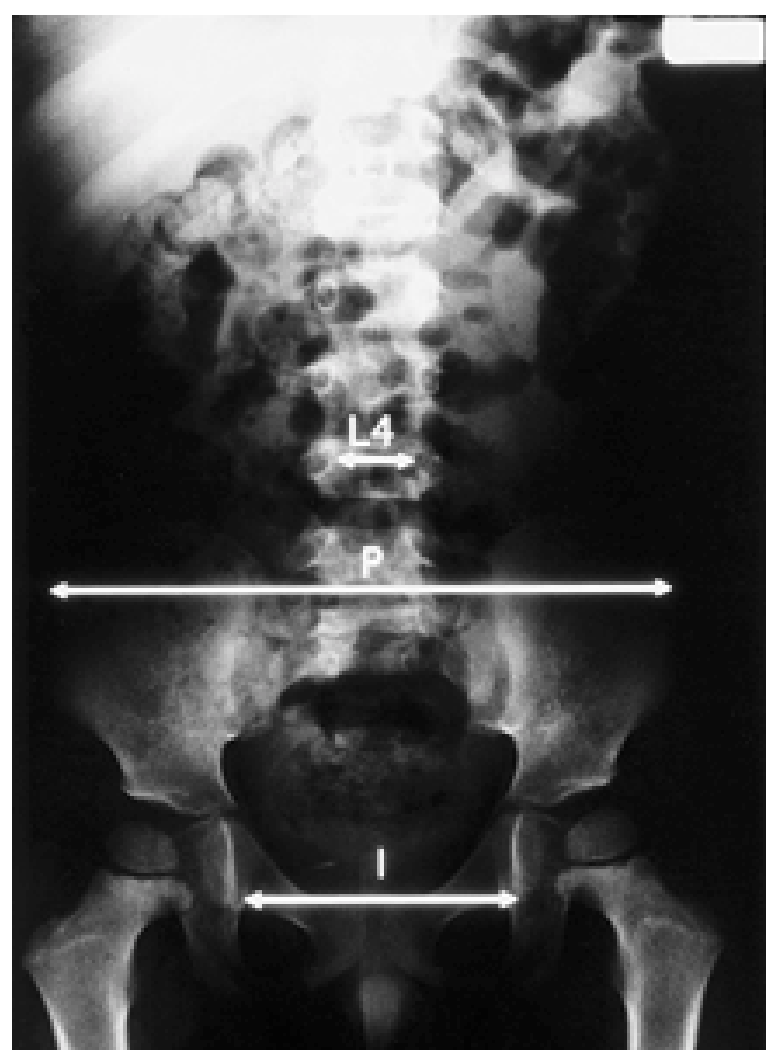

Fig. 1 Representative radiograph shows the ratio of the interpedicular distances at the first $\left(\mathrm{L}_{1}\right)$ and fourth $\left(\mathrm{L}_{4}\right)$ lumbar vertebrae $\left(\mathrm{L}_{1} /\right.$ $\mathrm{L}_{4}$ ratio) and the ratio of the interteardrop distance to the pelvic width (I/P ratio).
The mean SD score of height and sitting height in the N540K-negative subgroup was $-3.39 \pm 1.19$ and $-2.39 \pm 0.76$, respectively, which showed the similar changes to those of the N540K-positive subgroup, $-3.25 \pm 0.44$ and $-2.06 \pm 0.57$, respectively. The mean $\mathrm{SD}$ score of $\mathrm{SH} / \mathrm{LL}$ ratio and head circumference in the N540K-negative subgroup was $2.19 \pm 2.25$ and $-0.95 \pm 1.78$, respectively, which were at considerably lower than those of the N540K-positive subgroup, $7.42 \pm$ 0.54 and $1.88 \pm 0.07$, respectively (Fig. 2). The mean $\mathrm{L}_{1} / \mathrm{L}_{4}$ ratio in the $\mathrm{N} 540 \mathrm{~K}$-negative subgroup was $0.958 \pm 0.041$, which was higher than that of normal controls, $0.843 \pm 0.053$, though overlapping in several subjects, and lower than those of the N540K-positive subgroup, $1.081 \pm$ 0.034 , and achondroplasia patients, $1.243 \pm 0.123$. The mean $\mathrm{I} / \mathrm{P}$ ratio in the $\mathrm{N} 540 \mathrm{~K}$-negative subgroup was $0.380 \pm 0.016$ which showed no difference between those of the N540K-positive subgroup, $0.398 \pm 0.006$, and normal controls, $0.369 \pm 0.027$ (Fig. 3)

\section{Discussion}

The present study confirmed the view that hypochondroplasia is a clinically heterogeneous
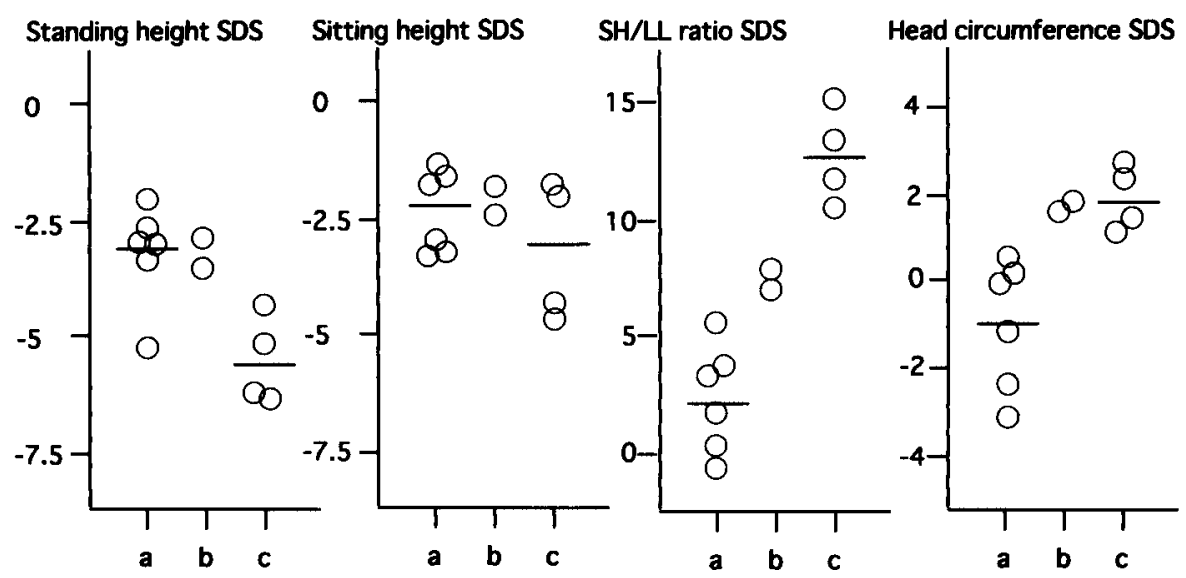

Fig. 2 The standard deviation score (SDS) of height, sitting height, SH/LL ratio and head circumference in patients with N540K-negative hypochondroplasia (Lane a), N540K-positive hypochondroplasia (Lane b) and achondroplasia (Lane c). Bars show the mean in each group. 

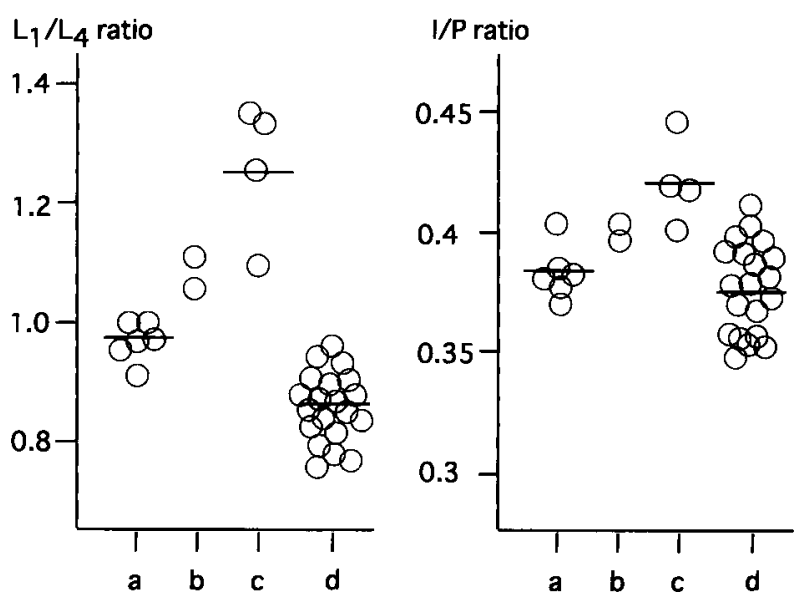

Fig. 3 The $L_{1} / L_{4}$ ratio and the $\mathrm{I} / \mathrm{P}$ ratio in patients with N540K-negative hypochondroplasia (Lane a), N540K-positive hypochondroplasia (Lane b), achondroplasia (Lane c) and the normal control group (Lane d). Bars show the mean in each group.

condition and that patients negative for the N540K mutation have less severe auxological and radiological features as previously described $(5,9)$. The six N540K-negative patients presented with short stature with less obvious disproportion, emphasizing the difficulties in unequivocally diagnosing hypochondroplasia without more extensive molecular analysis.

\section{References}

1. Hall BD, Spranger J. Hypochondroplasia: Clinical and radiological aspects in 39 cases. Radiology 1979; 133: 95-100.

2. Wynne-Davis R, Walsh WK, Gormley J. Achondroplasia and hypochondroplasia: Clinical variation and spinal stenosis. J Bone Joint Surg 1981; 63-B: 508-15.

3. Bellus GA, McIntosh I, Smith EA, Aylsworth AS, et al. A recurrent mutation in the tyrosine kinase domain of fibroblast growth factor receptor 3 causes hypochondroplasia. Nat Genet 1995; 10 : 357-9.

4. Prinos P, Costa T, Sommer A, Kilpatrick MW, et al. A common FGFR3 gene mutation in hypochondroplasia. Hum Molec Genet 1995; 4: 2097-101.

5. Prinster C, Carrera P, Del Maschio M, Weber G, et al. Comparison of clinical-radiological and molecular findings in hypochondroplasia. Am J Med Genet 1998; 75: 109-12.

6. Ministry of Health and Welfare: report of the 1990 national growth survey of normal Japanese children, 5-18 years of age. 1991

7. Matsui Y, Yasui N, Kimura T, Tsumaki $\mathrm{N}$, et al. Genotype phenotype correlation in achondroplasia and hypochondroplasia. J Bone Joint Surg 1998; 80-B: 1052-6.

8. Shiang R, Thompson LM, Zhu Y-Z, Church DM, et $a l$. Mutations in the transmembrane domain of FGFR3 cause the most common genetic form of dwarfism, achondroplasia. Cell 1994; 78: 335-42.

9. Ramaswami U, Rumsby G, Hindmarsh PC, Brook CGD. Genotype and phenotype in hypochondroplasia. J Pediatr 1998; 133: 99-102. 